\title{
Proactive Selective Response Suppression Is Implemented via the Basal Ganglia
}

\author{
D. S. Adnan Majid, ${ }^{1,2}$ Weidong Cai, ${ }^{1}$ Jody Corey-Bloom, ${ }^{3}$ and Adam R. Aron ${ }^{1,2}$ \\ ${ }^{1}$ Department of Psychology, ${ }^{2}$ Neurosciences Graduate Program, and ${ }^{3}$ Department of Neurosciences, University of California San Diego, La Jolla, California \\ 92093
}

In the welter of everyday life, people can stop particular response tendencies without affecting others. A key requirement for such selective suppression is that subjects know in advance which responses need stopping. We hypothesized that proactively setting up and implementing selective suppression relies on the basal ganglia and, specifically, regions consistent with the inhibitory indirect pathway for which there is scant functional evidence in humans. Consistent with this hypothesis, we show, first, that the degree of proactive motor suppression when preparing to stop selectively (indexed by transcranial magnetic stimulation) corresponds to striatal, pallidal, and frontal activation (indexed by functional MRI). Second, we demonstrate that greater striatal activation at the time of selective stopping correlates with greater behavioral selectivity. Third, we show that people with striatal and pallidal volume reductions (those with premanifest Huntington's disease) have both absent proactive motor suppression and impaired behavioral selectivity when stopping. Thus, stopping goals are used to proactively set up specific basal ganglia channels that may then be triggered to implement selective suppression. By linking this suppression to the striatum and pallidum, these results provide compelling functional evidence in humans of the basal ganglia's inhibitory indirect pathway.

\section{Introduction}

Stopping action can occur in several forms. A simple form of stopping occurs in reaction to an infrequent external signal (Verbruggen and Logan, 2008, Chambers et al., 2009, Boehler et al., 2010). Such reactive stopping has broad motor effects, suggesting use of a global inhibitory mechanism (Badry et al., 2009, Majid et al., 2012, Cai et al., 2012, Greenhouse et al., 2012). Some circumstances, however, may demand selective stopping targeted at a particular response (Aron and Verbruggen, 2008, Majid et al., 2012). Experimentally, this can be induced by requiring the subject to initiate two responses and then stopping one while continuing the other. For such stopping to be truly mechanistically selective, as opposed to nonselectively stopping all responses before reinitiating the one that must continue (cf. Bissett and Logan, 2013), it appears critical that subjects use stopping goals to prepare in advance which response channels might have to be stopped (Claffey et al., 2010, Cai et al., 2011). We refer to this as "proactive selective stopping." As this reflects a more ecologically valid form of control than simple reactive stopping (Aron, 2011), understanding its neural correlates could have wider implications, especially for disorders of response control.

Received Dec. 10, 2012; revised May 26, 2013; accepted June 2, 2013.

Author contributions: D.S.A.M., W.C., and A.R.A. designed research; D.S.A.M. and W.C. performed research; J.C.-B. contributed unpublished reagents/analytic tools; D.S.A.M. analyzed data; D.S.A.M. and A.R.A. wrote the paper.

This work was supported by NIH Grants DA 026452 and F31 NS077560, the Alfred P. Sloan Foundation, and CHDI. We thank Jody Goldstein and Cait Casey for subject recruitment, Rogier Mars for providing fMRI optimization scripts, and $\mathrm{Yu}$-Chin Chiu for comments on this manuscript.

Correspondence should be addressed to Adam R. Aron, Department of Psychology, University of California, San Diego, 9500 Gilman Drive, La Jolla, CA 92093. E-mail: adamaron@ucsd.edu.

DOI:10.1523/JNEUROSCI.5651-12.2013

Copyright $\odot 2013$ the authors $\quad 0270-6474 / 13 / 3313259-11 \$ 15.00 / 0$
Here we hypothesized that proactive selective stopping is implemented via fronto-basal ganglia signaling through the striatum and pallidum. These nodes are involved in two classical basal ganglia pathways: the direct and indirect pathways. The indirect pathway is of particular relevance to proactive selective stopping because its net effect after thalamocortical drive is inhibitory and it has the appropriate anatomical selectivity (Hazrati and Parent, 1992, Albin et al., 1995). Whereas this pathway features prominently in movement disorders and cognitive neuroscience alike (Penney and Young, 1983, Vonsattel et al., 1985, Mink, 1996, Jahfari et al., 2011), functional evidence in humans is scant. This is because of limitations in imaging resolution, the paucity of behavioral tasks known to engage selective stopping, and the difficulty in showing that a neural substrate in humans is necessary for behavior.

Using a behavioral paradigm for examining proactive selective stopping, wherein each trial has both a preparing-to-stop and an outright-stopping phase (Aron and Verbruggen, 2008, Cai et al., 2011, Majid et al., 2012), we investigated the underlying neural mechanisms with three methods. First, we used single-pulse transcranial magnetic stimulation (TMS) over the motor cortex as a probe of corticomotor excitability. We aimed to replicate our previous result (Cai et al., 2011) of proactive suppression of response channels when preparing to stop selectively. Second, we used fMRI in the same subjects to test whether (1) proactive suppression measured by TMS would correspond to striatal and pallidal fMRI activation (indicating that basal ganglia channels are used to set up proactive suppression) and (2) whether these basal ganglia "suppression channels" would be retriggered when stopping outright. Third, we aimed to evaluate whether striatum and pallidum are necessary for proactive selective stopping by 
studying premanifest Huntington's disease (preHD) individuals who have MRIconfirmed damage of these structures, examining whether they are impaired in proactive selective stopping compared with matched controls.

\section{Materials and Methods}

Subjects

Experiment 1. Eighteen healthy right-handed subjects ( 8 males, 10 females; mean age, $21.6 \pm$ 2.4 years) participated in a TMS session and an fMRI session. All subjects provided written consent in accordance with the Institutional Review Board (IRB) guidelines of the University of California, San Diego (UCSD). They also completed a TMS safety-screening questionnaire (Rossi et al., 2009) and an fMRI safety-screening form. Subjects had no history of neurological or psychiatric disorder.

Experiment 2. Sixteen right-handed HDpositive subjects took part; two subjects were excluded (one was an outlier on behavior, the other was given a diagnosis of manifest HD), leaving a group of 14 premanifest HD subjects (4 males, 10 females). The mean CAG repeat length of the mutant HD-gene allele was $43.0 \pm 2.8$ repeats. Based on this, preHD subjects were predicted to be $11.1 \pm 6.0$ years from disease onset (Langbehn et al., 2004, Langbehn et al., 2010). There were 15 controls (eight males, seven females), matched on age (preHD, $43.4 \pm 13.4$ years; controls, $42.0 \pm 12.6$ years; $t<1$ ), education (preHD, $14.1 \pm 2.4$ years; controls, $15.3 \pm 2.4$ years; $t_{(27)}=$ 1.421; n.s.), the Mini Mental Status Exam (MMSE; preHD, $28.2 \pm 2.2$ points of 30; controls, $28.5 \pm 1.6$ points of $30 ; t<1$ ) (Folstein et al., 1975), and the Montreal Cognitive Assessment (MoCA; preHD, $26.4 \pm$ 2.5 points of 30 ; controls, $27.0 \pm 2.5$ points of $30 ; t<1$ ) (Nasreddine et al., 2005). All subjects provided written consent in accordance with UCSD IRB guidelines and completed the safety screening form. Subjects were not taking neuropsychiatric drugs and had no neurological condition besides preHD status. At the time of the TMS experiment, the experimenter was blind to the genetic diagnosis of the preHD group.

\section{Selective stop-signal task}

Experiment 1 TMS version. We used the selective stop-signal task, adapted from Cai et al. (2011), in which subjects initiated a two-hand response on each trial but tried to stop one of the two responses in the case of an infrequent stop-signal (Fig. 1A). A key characteristic of this task is that each trial consists of two separate phases: a preparing-to-stop phase, where subjects must prepare in advance the hand that might need to stop, and an outright-stopping phase in which the response is made.

After an instruction session and two practice blocks, subjects performed 12 blocks proper. Each block had 48 trials. On each trial, subjects prepared by placing index and little fingers of each hand on four buttons. The two index fingers made up "inner" responses, whereas the two little fingers made up "outer" responses. Trials began with a cue [i.e., Maybe Stop Right (MSR), Maybe Stop Left (MSL), or Null] written in white on a black background for $500 \mathrm{~ms}$. The MSR and MSL cues (20 trials each per block) instructed subjects to prepare to stop a particular hand in the case of a stop-signal later in the trial. The Null trials (8 per block) indicated that no response would be necessary and provided a TMS baseline.

After the cue, the screen then turned blank for an average of $4 \mathrm{~s}$ before go-signal onset (range, 1.5-7 s). Single-pulse TMS was delivered over the motor cortex representation of the right hand on every trial during this cue-stimulus interval, $1 \mathrm{~s}$ after the cue offset (Fig. $1 B$ ). This served to index the corticomotor excitability of the right-hand motor representation at a given moment (see below for more details). This early $1 \mathrm{~s}$ stimulation time was of particular interest because it was the very time point at which we had previously identified proactive hand suppression in a task paradigm with a fixed $1.5 \mathrm{~s}$ cue-stimulus interval (Cai et al., 2011).
We aimed to replicate those findings, albeit using a slower task design where the cue-stimulus interval was extended and jittered. This was an important design consideration for the subsequent fMRI session.

After the preparatory period, an imperative Go stimulus was presented on MSR and MSL trials. This consisted of four horizontally arranged circles with two circles colored blue, indicating either a bimanual inner or outer finger response (equal probabilities). Failure to respond with both hands simultaneously (defined as $>70 \mathrm{~ms}$ difference in response times) resulted in a "decoupled" warning presented for $1 \mathrm{~s}$. The intertrial interval was a fixed $1 \mathrm{~s}$. On Go trials (50\% of trials, 10 MSR, 10 MSL per block), the circles remained until a response was made or $1 \mathrm{~s}$ had passed. On Stop trials (25\% of trials, five MSR, five MSL per block), a red X appeared in the center of the screen after a short stop-signal delay (SSD) and remained until the end of the trial. Subjects were required to stop the response of the hand previously cued at the beginning of the trial while quickly continuing with the other hand.

Note that some trials were so-called "Partial trials" (25\% of trials, five MSR, five MSL per block), in which the screen remained blank until the end of the trial. These trials, requiring stopping preparation without a subsequent response, were important to statistically isolate the neural contribution of the preparation phase in the fMRI session (Ollinger et al., 2001) but were also used in the TMS session for task consistency.

The SSD dynamically varied throughout the experiment, increasing or decreasing by $50 \mathrm{~ms}$ with every successful or failed stop, respectively, leading to an approximate probability of stopping of $50 \%$. The stopsignal reaction time (SSRT) was calculated using the integration method (Verbruggen and Logan, 2009). Additional behavioral measures included the accuracy and rate of decoupling on Go trials, the probability of stopping successfully on Stop trials, the stopping direction error rate (how many times the subject stopped the incorrect hand), median Go reaction time (RT), median RT on failed Stop trials, and median RT of the unstopped continuing hand on Stop trials (the Continuing RT).

The Stopping Interference Effect indexes the selectivity of stopping (Aron and Verbruggen, 2008). We estimated this effect as the median RT of the continuing hand (when the other hand is stopped) minus the median RT of that same hand on analogous Go trials. These analogous Go trials were determined by rank-ordering the Go RTs and averaging those RTs longer than the $n$th one, where $n$ is obtained by multiplying the number Go RTs in the distribution by the probability of failing to stop on Stop trials. This method provides a more accurate estimate of the Stopping Interference Effect as it accounts for the fact that the Go process on 
successful Stop trials will be slower than that of all Go trials (Verbruggen and Logan, 2009).

Experiment 1 fMRI version. There were three short practice blocks outside the scanner and four blocks within the scanner. Task details were similar to the TMS procedure, with a few differences. Each scanner block was made up of 48 trials with four equiprobable cues [MSR, MSL, Maybe Stop Both (MSB), and Just Go (JG)]. There was no Null cue, but the JG condition served as a comparable baseline by assuring subjects that no stop-signal would occur on that trial. MSR and MSL were selective stopping cues, whereas MSB was a nonselective stopping cue indicating that subjects should stop both hand responses in the case of a stop-signal. We have previously shown that stopping in the MSB condition has a physiological profile akin to simple reactive stopping for which proactive selective preparation would be unlikely (cf. Majid et al., 2012). Thus, the MSB served as an additional control condition.

For the MSR, MSL, and MSB conditions, $50 \%$ of trials were Go trials (six trials per condition per block), $25 \%$ were Stop trials (three trials per condition per block), and 25\% were Partial trials (three trials per condition per block). For the JG condition, $75 \%$ of trials were Go trials (nine trials per block) and 25\% were Partial trials (three trials per block). The intertrial interval was jittered from 1 to $5 \mathrm{~s}$ (mean, $3 \mathrm{~s}$ ).

Experiment 2 TMS version. There were three practice blocks followed by eight blocks proper of the TMS task. There were a few differences compared with TMS in Experiment 1. Each block was made up of 30 trials with five equiprobable cues (MSR, MSL, MSB, JG, and the Null baseline; six trials per condition). In addition to the Null baseline, the JG and MSB conditions served as additional control conditions for which proactive selective motor suppression was not expected (cf. Majid et al., 2012). Cues were presented for $500 \mathrm{~ms}$. After cue offset, the screen remained blank for a fixed $1.5 \mathrm{~s}$ period until the go-signal, and TMS was always delivered $1 \mathrm{~s}$ after cue offset (exactly $500 \mathrm{~ms}$ before the go-signal) on each trial. These timing parameters matched those of Cai et al. (2011), for which proactive suppression was demonstrated at the group level, since fMRI design considerations were not relevant for Experiment 2. Accordingly, there were also no Partial trials. Stop trials thus occurred on $33 \%$ of all MSR, MSL, and MSB trials (two per block per condition).

\section{TMS}

EMG recordings. The subjects sat about $50 \mathrm{~cm}$ in front of a 19-inch monitor with their hands placed on a four-keypad response devise (two vertical keypads for index-finger responses flanked by two horizontal keypads for little-finger responses). Surface electromyography (EMG) was recorded using a pair of $10 \mathrm{~mm}$ silver electrodes from the first dorsal interosseous (FDI) of the right hand, optimal on account of this muscle's role in the right-hand index response. A ground electrode was placed over the radial wrist protuberance of the right hand.

A Glass QP511 Quad AC Amplifier System (Glass Technologies) amplified the EMG signal using a $30 \mathrm{~Hz}$ to $1 \mathrm{kHz}$ bandpass filter and a $60 \mathrm{~Hz}$ notch filter. A CED Micro $1401 \mathrm{mk}$ II acquisition system sampled the data at a frequency of $2 \mathrm{kHz}$. Data were recorded using CED Signal version 4 (Cambridge Electronic Design).

TMS delivery. Transcranial magnetic stimulation was delivered with a MagStim 200-2 system (Magstim) and a figure-of-eight coil (7 cm diameter). The study began with a thresholding procedure in which subjects sat with their hand resting on the table. The coil was initially placed $\sim 5$ $\mathrm{cm}$ left and $2 \mathrm{~cm}$ anterior to the vertex to find the cortical representation of the right FDI muscle. With single-pulse stimulation, the coil was incrementally repositioned, and the stimulation intensity was incrementally increased until a reliable motor evoked-potential (MEP) was obtained in the right FDI. The amplitude of this MEP served as an index of the excitability of the corticomotor representation of the right hand at a particular point in time.

The lowest stimulation level required to elicit MEP amplitudes of at least $0.05 \mathrm{mV}$ in at least 5 of 10 trials was determined as the resting motor threshold (Rossini et al., 1994). The exact location of stimulation was marked on the scalp for future reference. The experimental stimulation intensity for use throughout the study was determined as the stimulation level that consistently elicited MEP amplitudes that were approximately half the size of the subject's maximum MEP amplitude. This ensured that both increases and decreases in corticomotor excitability could be optimally identified, because subject responses to TMS theoretically fell on the steepest limb of the subject's stimulation-response curve (Devanne et al., 1997). The mean experimental stimulation intensity as a percentage of maximum simulator output was $51.2 \pm 8.1 \%$ for Experiment 1 and $48.5 \pm 9.1 \%$ for Experiment 2 .

Analysis. Peak-to-peak MEP amplitude was determined using custom MATLAB software. Trials were excluded if the root mean square of EMG activity in the $100 \mathrm{~ms}$ before TMS delivery was $>10 \mu \mathrm{V}$ to ensure no preliminary hand activation. MEP amplitudes for each condition (MSR, MSL, or Null, with the addition of MSB or JG in Experiment 2) were then trimmed to ensure distribution normality (by removing the upper and lower 10\% of values) (Wilcox, 2001, Stinear and Byblow, 2004) and averaged. Percent Hand Modulation, a measure of right-hand motor excitability change compared with the Null baseline $1 \mathrm{~s}$ after cue offset, was determined for all non-Null conditions using the following formula: (Condition MEP - Null MEP)/Null MEP $\times 100 \%$. Negative Percent Hand Modulation on MSR trials indicates proactive motor suppression of the hand that might need to stop later in the trial. The same analysis was run on the root mean square EMG measure to ensure that there were no significant group or condition differences before TMS was delivered.

\section{Functional MRI}

Task optimization. Custom software implemented in SPM2 (http://www. fil.ion.ucl.ac.uk/spm/) simulated the optimal trial event order, cuestimulus interval lengths, and intertrial interval lengths for each scan before the fMRI session. This kept the correlation between different trial regressors below $33 \%$, so that we could separate the BOLD response in the preparing-to-stop and outright-stopping phases.

Data acquisition. We used a 3T GE MR750 scanner equipped with an eight-channel head coil at the UCSD Keck Center for Functional MRI. A $\mathrm{T}_{1}$-weighted sequence with $1 \mathrm{~mm}^{3}$ resolution was used to acquire anatomical images (TR, $8092 \mathrm{~ms}$; TE, $3.164 \mathrm{~ms}$; TI, $600 \mathrm{~ms}$; 178 slices; flip angle, $8^{\circ}$ ). Two hundred nine functional $\mathrm{T}_{2}^{*}$-weighted echoplanar images (EPIs) were acquired for each of the four scanning runs with a $4 \mathrm{~mm}$ slice thickness (TR, $2000 \mathrm{~ms}$; TE, $32 \mathrm{~ms}$; flip angle, $90^{\circ}$; image matrix, $64 \times 64$; FOV, $220 \times 220 \mathrm{~mm}$; voxel size, $4 \times 3.44 \times 3.44 \mathrm{~mm}$ ). The first four volumes were discarded to allow for $\mathrm{T}_{1}$ equilibrium effects. A single field map image was obtained (TR, $500 \mathrm{~ms}$; TE, $8.5 \mathrm{~ms}$; flip angle, $45^{\circ}$; same FOV as EPI) to correct for gradient distortions using custom software.

Preprocessing, general linear modeling, and analysis. The data were processed using FSL software (www.fmrib.ox.ac.uk/fsl). The functional images were realigned to correct for small head movements (Jenkinson et al., 2002). A $5 \mathrm{~mm}$ full-width half-maximum Gaussian kernel was then used to spatially smooth the data, which was subsequently high-pass filtered using a $100 \mathrm{~s}$ cutoff. EPIs were first registered to the $\mathrm{T}_{1}$ structural image and then nonlinearly registered to a standard 2 mm MNI152 template using 12 degrees of freedom (Jenkinson and Smith, 2001).

For each scan of each subject, data were fitted with two different models, basic or parametric. In the basic model, the MSR and MSL conditions were merged into a single selective stopping condition $(\mathrm{MSR}+\mathrm{L})$, in addition to the MSB and JG conditions. Fourteen separate events were modeled overall. The preparing-to-stop phase was modeled by three "Cue" events (500 ms each, for the MSR+L, MSB, and JG conditions, respectively) that began at the preparatory cue onset. The outrightstopping phase was modeled by eleven events ( $1 \mathrm{~s}$ each) that began at the end of the variable cue-stimulus interval: three "Go" events (for correct bimanual responses on MSR $+\mathrm{L}, \mathrm{MSB}$, and JG Go trials, two "Stop" events (for successful inhibition on MSR $+\mathrm{L}$ and MSB Stop trials), two "Fail" events (for unsuccessful inhibition on MSR $+\mathrm{L}$ and MSB Stop trials), three "Partial" events (for MSR +L, MSB, and JG Partial trials), and a nuisance event for all other occurrences. The parametric model was the same as the basic model with the addition of a regressor for the Continuing RT on successfully inhibited MSR + L stop trials (Stop_ RT_param). Since this regressor was demeaned, it was statistically identical to a trial-by-trial regressor of the Stopping Interference Effect, where the Continuing RT of a particular successful Stop trial is subtracted by the subject's average Go RT. The Go RT for an individual subject was stable 


\begin{tabular}{|c|c|c|c|c|}
\hline & \multicolumn{2}{|c|}{ Experiment $1(n=18)$} & \multicolumn{2}{|l|}{ Experiment 2} \\
\hline & TMS task & fMRI task & Controls $(n=15)$ & $\operatorname{PreHD}(n=14)$ \\
\hline \multicolumn{5}{|l|}{ Behavior (selective stop condition) } \\
\hline Go RT (ms) & $611 \pm 90$ & $614 \pm 81$ & $863 \pm 209$ & $1100 \pm 285^{*}$ \\
\hline Go decoupling rate (\%) & $7.6 \pm 4.8$ & $3.9 \pm 4.2$ & $6.2 \pm 3.3$ & $11.5 \pm 10.4$ \\
\hline Stop probability (\%) & $50.3 \pm 5.8$ & $53.0 \pm 11.8$ & $57.0 \pm 7.8$ & $62.8 \pm 8.1$ \\
\hline Stopping direction errors (\%) & $3.5 \pm 3.8$ & $5.6 \pm 7.6$ & $2.0 \pm 2.8$ & $3.4 \pm 3.5$ \\
\hline Failed stopping RT (ms) & $559 \pm 76$ & $551 \pm 71$ & $720 \pm 159$ & $949 \pm 498$ \\
\hline SSD (ms) & $310 \pm 61$ & $337 \pm 60$ & $543 \pm 142$ & $630 \pm 143$ \\
\hline SSRT (ms) & $282 \pm 61$ & $251 \pm 44$ & $292 \pm 94$ & $405 \pm 290$ \\
\hline \multicolumn{5}{|l|}{ TMS } \\
\hline Resting motor threshold (\% of max) & $46.2 \pm 7.8$ & $\mathrm{~N} / \mathrm{A}$ & $41.2 \pm 6.9$ & $47.3 \pm 9.8$ \\
\hline Stimulation level (\% of maximum) & $51.2 \pm 8.1$ & $\mathrm{~N} / \mathrm{A}$ & $45.5 \pm 7.2$ & $52.4 \pm 9.8$ \\
\hline MSL MEP modulation (\%) & $16.9 \pm 37.2$ & $\mathrm{~N} / \mathrm{A}$ & $3.5 \pm 24.3$ & $6.5 \pm 18.3$ \\
\hline
\end{tabular}

Values given as average \pm SD. MEP, mean motor evoked potential amplitude (trimmed) for a given condition. MEP Modulation (percentage) is calculated as follows: (MSR or MSL MEP - Null MEP)/(Null MEP) $\times 100 \%$. For Experiment 2 asterisks represent significant differences between preHD and controls at the ${ }^{*} p<0.05$ and ${ }^{* *} p<0.01$ levels. See Materials and Methods for details regarding the calculation of the Stopping Interference Effect.

throughout the fMRI experiment, and this regressor did not differ appreciably from that of a more local estimate of the Stopping Interference Effect, where the Continuing RT for a particular successful Stop trial was subtracted by the average Go RT of the three correct Go trials before and after the Stop trial.

For the preparing to stop phase, we contrasted MSR $+\mathrm{L}>\mathrm{JG}$ preparation using the basic model. For the outright stopping phase, we contrasted MSR $+\mathrm{L}$ (Stop $>$ Go) using the basic model and MSR $+\mathrm{L}$ Stop_RT_param $>$ Null using the parametric model.

Analysis was performed using the FSL tool FEAT (fMRI Expert Analysis Tool). For each subject, a higher-level fixed-effects analysis was used to combine contrasts from the four different scanner runs. FMRIB's Local Analysis of Mixed Effects (FLAME) tool with automatic outlier deweighting was used for a mixed-effects group average (one-sample $t$ tests). FLAME was also used in a group-wise regression of individual Percent Hand Modulation measures and subject activation. A basal ganglia mask in MNI152 standard space, and derived from the Harvard/ Oxford Atlas in FSL, was used for some analyses. This included all of the caudate, putamen, and pallidum.

\section{Structural MRI analysis for Experiment 2}

Nine of the 14 preHD subjects (two males, seven females) had taken part in a previous study $(2.6 \pm 0.2$ years prior $)$ that included structural imaging (Majid et al., 2011b). In that study, there were also 22 matched controls. Here we reanalyzed the data derived from automated volumetric segmentation, using FreeSurfer (Fischl et al., 2002, Fischl et al., 2004), of $\mathrm{T}_{1}$-weighted images (from that study's second visit). We analyzed data from seven subcortical structures (namely accumbens, amygdala, caudate, hippocampus, pallidum, putamen, and thalamus). Bilateral structural volumes were summed and normalized to each subject's total intracranial volume (ICV). Group difference statistics were corrected for multiple comparisons using the strict Bonferroni's method.

The nine preHD subjects who had taken part in the imaging study did not differ significantly from the five who did not with regard to any measure, whether age $(46.0 \pm 15.8$ vs $38.8 \pm 6.9$ years old, $t<1)$ or mutant CAG repeat length $(42.8 \pm 3.2$ vs $43.4 \pm 2.3$ repeats, $t<1)$.

\section{Results}

\section{Experiment 1: TMS and fMRI in young volunteers}

In the TMS session, Go RT was $611 \pm 90 \mathrm{~ms}$, the probability of stopping was $50.3 \pm 5.8 \%$, the speed of stopping (SSRT) was $282 \pm 61 \mathrm{~ms}$, and the Stopping Interference Effect was $68 \pm 63 \mathrm{~ms}$ (Table 1).
As a likely consequence of having lengthened the task timing parameters to match the fMRI session, proactive right-hand suppression on MSR trials (i.e., negative MSR Percent Hand Modulation) was not now seen at the group level whereas it had been in the study by Cai et al. (2011), which used a fixed and much shorter cue-stimulus interval. Instead, there was very high variability across subjects, ranging from -33.4 to $42.7 \%$ even after the removal of a statistical outlier (group mean, $4.4 \pm 20.6 \% ; n=17$ ). Conveniently, however, this variability allowed us to relate TMS-measured physiology with fMRI-measured brain activation (see below).

All subjects later took part in an fMRI session (mean delay, $21.4 \pm 20.9$ days). The MSR and MSL conditions were combined into a single selective MSR $+\mathrm{L}$ condition to increase statistical power. For this condition, Go RT was $614 \pm 81 \mathrm{~ms}$, the probability of stopping was $53.0 \pm 11.8 \%$, SSRT was $251 \pm 44 \mathrm{~ms}$, and the Stopping Interference Effect was $60 \pm 56 \mathrm{~ms}$. These values compare very favorably with those of the TMS session (Table 1).

\section{Preparing-to-stop phase}

We hypothesized that the striatum and pallidum would be active in the MSR + L condition. At the overall group level, we contrasted MSR $+\mathrm{L}$ (preparation for selective stopping) with the JG baseline (preparation without any possible stopping). Consistent with our hypothesis, there was widespread activation in the bilateral putamen and pallidum, as well as premotor cortex, parietal cortex, occipital cortex, and left thalamus $(Z>2.3, p<0.05$, whole-brain cluster correction) (Fig. 2A, Table 2).

We then investigated whether this preparing-to-stop activation correlated with the TMS-derived proactive suppression $(n=$ 17 after the removal of the abovementioned statistical outlier). We hypothesized that subjects who were more able to suppress the right hand in the preparing-to-stop phase (i.e., with more negative MSR Percent Hand Modulation) would also show greater activation of striatum and pallidum in the analogous preparing-to-stop phase of the fMRI session. Consistent with our hypothesis, a group-wise regression analysis revealed greater activation in the left putamen and pallidum, as well as the left thalamus, supramarginal gyrus, presupplementary motor cortex (preSMA), and paracingulate gyrus in subjects who better sup- 


\section{MS Right + Left > Just Go Preparation}

\section{A Whole group average}
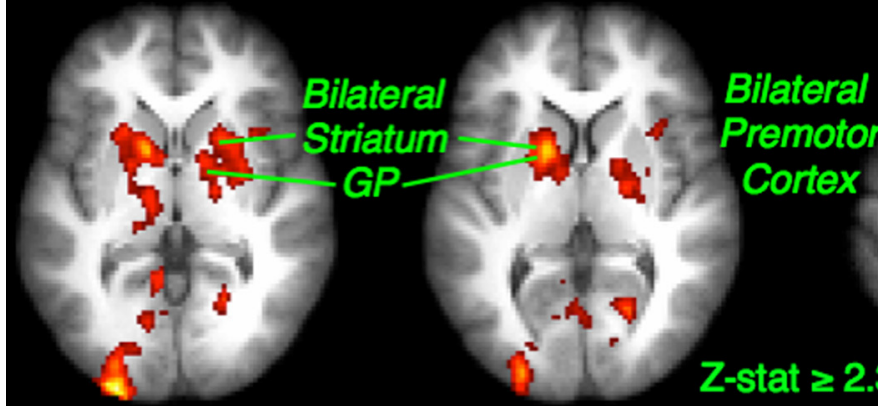

B Correlation to Proactive Hand Modulation
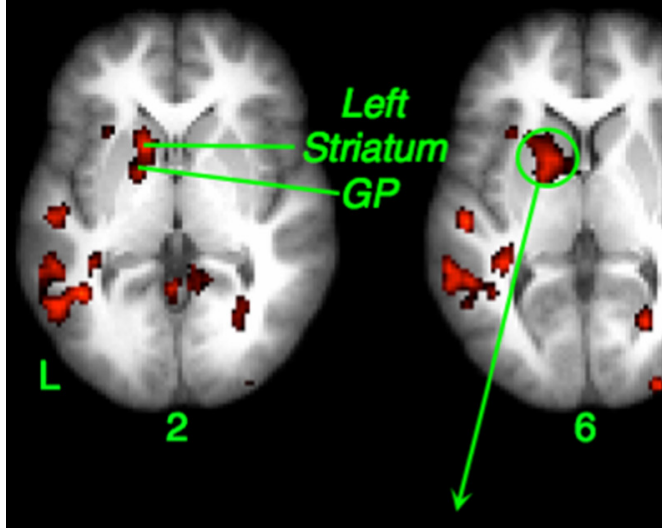

Presupplementany

Motor Area

(presMA)

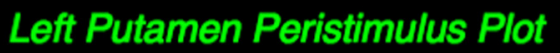

Left Putamen ROI (-18 64$)$
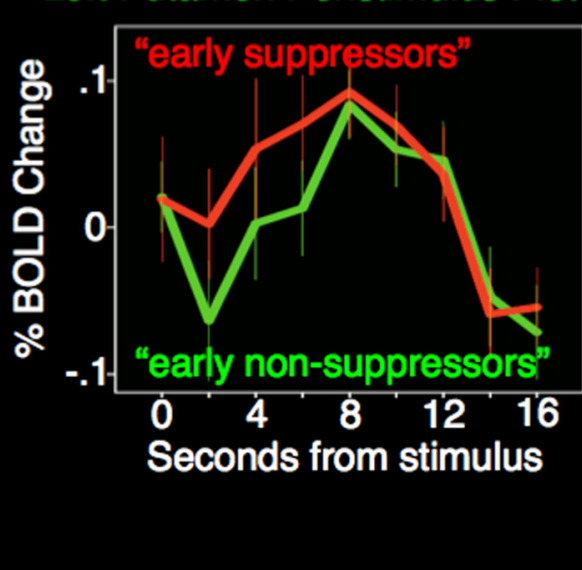

Figure 2. Experiment 1: preparing to stop selectively and motor suppression. $A$, Maybe Stop Right + Left $>$ Just Go preparatory activation. In the entire group, preparation to stop selectivity activated bilateral striatum, globus pallidus, and premotor cortex. $\boldsymbol{B}$, Group-wise regression of fMRI activation against TMS proactive suppression. In the TMS session, Percent Hand Modulation indexed the degree of top-down influence of the Maybe Stop Right stopping goal on right-hand motor channels compared with Null. This was calculated as follows: (Maybe Stop Right MEP - Null MEP)/Null MEP $\times 100 \%$. Activation in the left putamen, pallidum, and preSMA was greater in subjects who more readily suppressed the right hand when cued. Bottom left inset, Subject MSR Percent Hand Modulation plotted against mean activation in a left putamen ROI (4 mm radius) for descriptive purposes. Greater activation is seen in subjects with greater suppression. Bottom right inset, For the same left putamen ROI, peristimulus plots are shown for those subjects who showed proactive hand suppression at $1 \mathrm{~s}$ after cue offset ("early suppressors"; $n=9$ ), versus those who did not ("early nonsuppressors"; $n=8$ ). GP, Globus pallidus; L, left; R, right.

pressed the stopping hand $(Z>2.0, p<0.05$, whole-brain cluster correction) (Fig. $2 B$, Table 2).

Notably, the above results reveal that the subgroup of subjects who did not have TMS-measured proactive hand suppression also did not have striatum and pallidum activation (see Fig. $2 \mathrm{~B}$, bottom left, for descriptive plot of left putamen activation). We speculate that proactive suppression simply occurred later in the trial for these subjects (in both TMS and fMRI sessions). With a median split, we divided subjects into "early suppressor" $(n=9)$ and "early non-suppressor" $(n=8)$ groups based on the MSR Percent Hand Modulation measure. We then generated peristimulus plots for signal change after the onset of the selective stopping cue (MSR or MSL) for each group at the left putamen ROI that was shown in Figure $2 B$ (bottom left). The plots provide qualitative evidence that the rise in activation in the early nonsuppressor group occurs later, even though both groups peak around the same time (Fig. $2 \mathrm{~B}$, bottom right). This delayed activation, but eventual catch-up in early nonsuppressors suggests that they may, in fact, be "late suppressors" for whom proactive hand suppression was missed in the TMS task, and it explains in part why stopping behavior did not differ between groups.

We also included an MSB condition in the fMRI session as an additional control (as it does not require selective stopping). For the contrast of MSB $>$ JG, there was only limited left premotor and parietal activation $(Z>2.3, p<0.05$, whole-brain cluster correction) (Fig. $3 A$, Table 2), consistent with the fact that neither condition should engage regions for proactive selective suppression. For the MSR $+\mathrm{L}>\mathrm{MSB}$ contrast, there was bilateral dorsal caudate and thalamus activation, as well as the bilateral premotor and parietal cortices $(Z>2.3, p<0.05$, whole-brain cluster correction) (Fig. 3B, Table 2), consistent, again, with a striatal role in preparing to stop selectively.

\section{Outright-stopping phase}

We hypothesized that when the stop signal occurs, the basal ganglia should again be activated to implement stopping that is selectively targeted at a particular response tendency. To examine this, we contrasted successful Stop trials with Go trials in the MSR $+\mathrm{L}$ condition $(\mathrm{MSR}+\mathrm{L}$ Stop $>$ Go). There was activation of the basal ganglia, including bilateral ventral caudate and putamen, as well as thalamus, bilateral inferior frontal cortex (IFC), preSMA, orbitofrontal cortex (OFC), insular cortex, premotor cortex, and paracingulate cortex $(Z>2.3, p<0.05$, whole-brain cluster correction) (Fig. $4 A$, Table 3 ). Notably, this outright-stopping activation partially overlapped with activation in the MSR $+\mathrm{L}>\mathrm{JG}$ preparation contrast and also with the parametric preparation 
Table 2. Experiment 1 Activation coordinates for the Preparing-to-Stop phase

\begin{tabular}{|c|c|c|c|c|c|c|}
\hline Contrast & Region & Side & $x$ & $y$ & $z$ & Z-max \\
\hline \multirow[t]{12}{*}{ MSR $+\mathrm{L}>\mathrm{JG}$ preparation } & Premotor cortex & $\mathrm{L}$ & -44 & -8 & 34 & 4.63 \\
\hline & Premotor cortex & $\mathrm{R}$ & 26 & -6 & 44 & 4.48 \\
\hline & Superior frontal gyrus & $\mathrm{R}$ & 22 & 0 & 48 & 4.33 \\
\hline & Superior parietal lobule & $\mathrm{R}$ & 32 & -48 & 40 & 4.32 \\
\hline & Premotor cortex & $\mathrm{L}$ & -50 & 2 & 36 & 4.15 \\
\hline & Supramarginal gyrus & $\mathrm{L}$ & -42 & -44 & 42 & 4.00 \\
\hline & Occipital pole & $\mathrm{L}$ & -16 & -100 & -4 & 3.96 \\
\hline & Putamen & $\mathrm{R}$ & 22 & 8 & -10 & 3.55 \\
\hline & Presupplementary motor cortex & $\mathrm{L}$ & -10 & 6 & 44 & 3.52 \\
\hline & Pallidum & $\mathrm{L}$ & -22 & -2 & -4 & 3.39 \\
\hline & Putamen & $\mathrm{L}$ & -18 & 6 & 4 & 3.37 \\
\hline & Thalamus & $\mathrm{L}$ & -12 & -20 & -2 & 3.05 \\
\hline \multirow{6}{*}{$\begin{array}{l}\text { Correlation of MSR }+\mathrm{L}>\mathrm{JG} \text { preparation against degree } \\
\text { of proactive suppression in TMS task ( } n=17 \text { after } \\
\text { exclusion of a TMS outlier) }\end{array}$} & Temporo-parietal junction & $\mathrm{L}$ & -54 & -48 & 20 & 3.48 \\
\hline & Paracingulate gyrus & $\mathrm{L}$ & -4 & 18 & 46 & 3.37 \\
\hline & PreSMA & $\mathrm{R}$ & 6 & 20 & 52 & 3.02 \\
\hline & Thalamus & $\mathrm{L}$ & -18 & -24 & 16 & 2.85 \\
\hline & Putamen & $\mathrm{L}$ & -18 & 6 & 4 & 2.69 \\
\hline & Pallidum & $\mathrm{L}$ & -18 & 2 & 4 & 2.65 \\
\hline \multirow[t]{2}{*}{ MSB $>$ JG preparation } & Superior parietal lobule & $\mathrm{L}$ & -32 & -56 & 40 & 3.84 \\
\hline & Premotor cortex & $\mathrm{L}$ & -46 & 2 & 36 & 3.84 \\
\hline \multirow[t]{6}{*}{ MSR + L > MSB preparation } & Premotor cortex & $\mathrm{R}$ & 28 & -8 & 54 & 4.68 \\
\hline & Premotor cortex & $\mathrm{L}$ & -32 & -14 & 42 & 4.66 \\
\hline & Thalamus & $\mathrm{L}$ & -14 & -24 & 0 & 2.96 \\
\hline & Caudate & $\mathrm{L}$ & -12 & 4 & 14 & 2.90 \\
\hline & Caudate & $\mathrm{R}$ & 16 & 14 & 14 & 2.48 \\
\hline & Thalamus & $\mathrm{R}$ & 12 & -24 & 4 & 2.45 \\
\hline
\end{tabular}

contrast (i.e., where MSR $+\mathrm{L}>$ JG preparation correlated with proactive hand suppression from the TMS study). The regions of overlap for the latter were as follows: left caudate $(-10,8,8)$, putamen $(-16,8,-2)$, pallidum $(-12,4,0)$, insula $(-34,18,0)$, and the midline preSMA $(2$, $18,51)$.

Next, we examined whether the striatal activation during selective stopping was related to behavioral selectivity (operationalized as a minimal RT delay for the continuing hand movement, i.e., a small Stopping Interference Effect). For each subject, activity on MSR $+\mathrm{L}$ successful Stop trials was regressed against the continuing hand RT on those trials, and a group analysis was performed. We found that the greater the selectivity of stopping (smaller Stopping Interference Effect), the greater the activity in the bilateral dorsal head of caudate $(Z>2.3, p<0.05$, cluster corrected over a whole basal ganglia mask) (Fig. 4B, Table 3). This activation was unlikely simply attributable to the faster speed of the movement made on selective Stop trials; an analogous analysis in which activity on Go trials was regressed against RT on those trials did not reveal activity in the caudate even at a reduced cluster threshold $(Z>$ $1.8, p<0.05$, cluster corrected over a whole basal ganglia mask). Also, although this activation was more dorsal than the activation in the MSR $+\mathrm{L}$

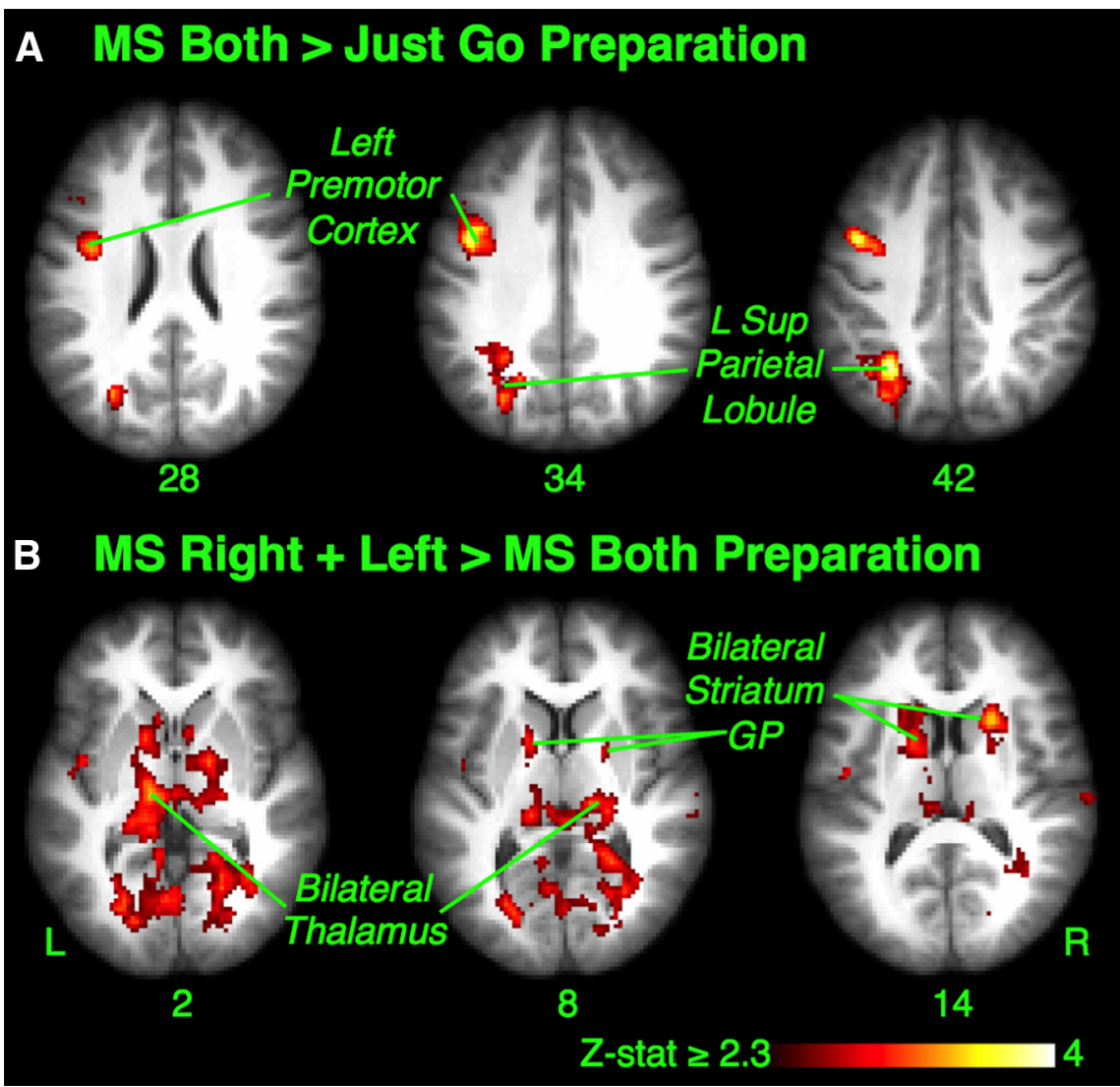

Figure 3. Experiment 1: preparing to stop (MSB condition). $\boldsymbol{A}$, Maybe Stop Both $>$ Just Go preparatory activation. There was activation of left premotor and parietal regions. $\boldsymbol{B}$, Maybe Stop Right + Left $>$ Maybe Stop Both preparatory activation. There was activation of bilateral dorsal caudate and thalamus, as well as bilateral premotor and parietal regions (not shown). GP, Globus pallidus; L, left; $R$, right. 


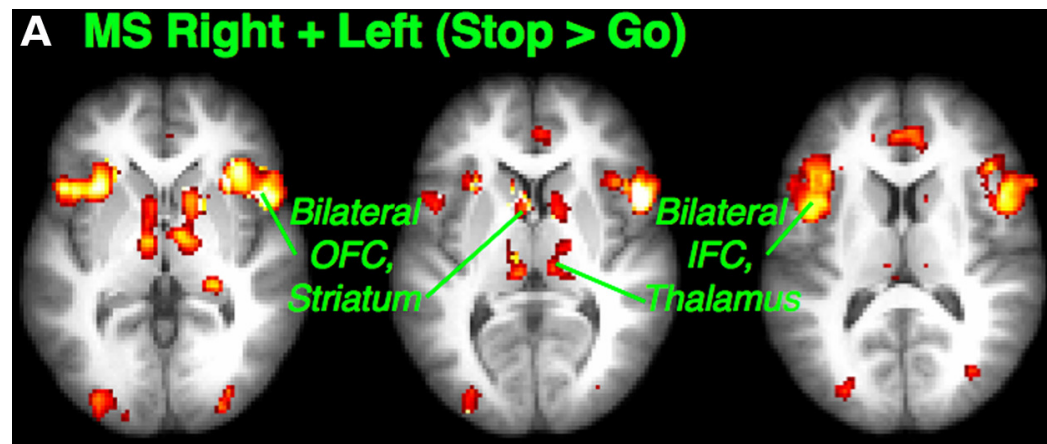

B Parametric Analysis of Interference

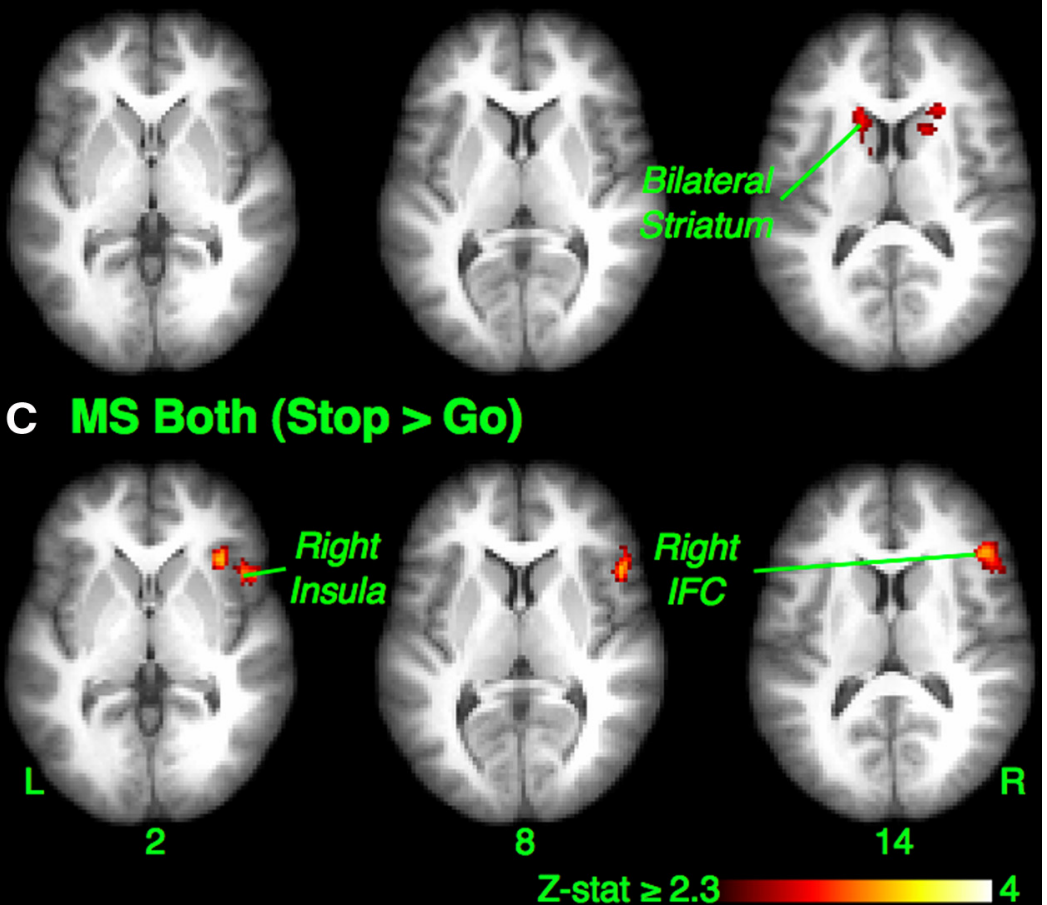

Figure 4. Experiment 1: outright-stopping phase. A, Maybe Stop Right + Left (Stop $>$ Go). When stopping needed to be selective, the comparison of successful Stop to Go trials showed wide activation, including the bilateral OFC, striatum, IFC, and thalamus. Premotor and supplementary motor cortices were also active (not shown). B, Parametric analysis: greater striatal activation with more selective stopping. Activation on successful MSR + LS Stop trials scaled parametrically with reduced stopping interference (i.e., faster continuing hand responses and greater selectivity). The bilateral head of caudate was identified (cluster correction over the whole basal ganglia mask). C, Maybe Stop Both (Stop $>$ Go). In the control condition where stopping did not need to be selective, comparison of successful Stop to Go trials showed restricted activation limited to the right inferior frontal cortex (rIFC), OFC, and insular cortex. L, Left; R, right.

Stop $>$ Go contrast, it overlapped considerably with the MSR $+\mathrm{L}>\mathrm{MSB}$ preparation contrast (right caudate: 14, 10, 16; left caudate: $-12,2,16$ ).

Outright stopping in the MSB condition again served as a control condition. Activation in the MSB Stop > Go contrast was only significant in the right inferior frontal cortex (rIFC), orbitofrontal cortex, and insular cortex (Fig. 4C, Table 3). This activation of right frontal cortex is consistent with many studies implicating this region in simple reactive stopping (Aron et al., 2004, Chamberlain et al., 2006, Chikazoe, 2010).

\section{Experiment 2: TMS in preHD versus controls}

The physiological and fMRI results of Experiment 1 show that the striatum and pallidum are active for proactive selective stopping. If these basal ganglia regions are necessary for this function, then damage to them in premanifest Huntington's disease should impair proactive selective stopping.

Indeed, the preHD group was behaviorally impaired in the selectivity of stopping, as there was an elevated Stopping Interference Effect (preHD, $467 \pm 330$ ms; controls, $221 \pm 183 \mathrm{~ms} ; t_{(27)}=2.508$; $p<.05)$. As Go RT was also longer in preHD (preHD, $1100 \pm 285 \mathrm{~ms}$; controls, $\left.863 \pm 209 \mathrm{~ms} ; t_{(27)}=2.566 ; p<0.05\right)$, we calculated a normalized measure of stopping selectivity by dividing the Stopping Interference Effect by Go RT for each subject. This normalized Stopping Interference Effect was also significantly elevated in preHD (preHD, $42.4 \pm 29.5 \%$; controls, $25.4 \pm 17.3 \% ; t_{(27)}=1.913 ; p<$ $0.05)$ (Fig. 5A, Table 1). Neither the probability of stopping nor SSRT differed significantly between groups.

Experiment 2 timing parameters matched those of our previous report wherein proactive suppression was demonstrated at the group level (Cai et al., 2011). Strikingly, proactive suppression after the MSR cue, determined using single-pulse TMS to index motor excitability in the preparing-to-stop phase, was absent in preHD but present in controls (Percent Hand Modulation; preHD: $6.5 \pm 15.7 \%$, one-sample $t_{(13)}=1.564$, n.s.; controls: $-7.8 \pm 11.9 \%$, one-sample $t_{(14)}=2.524, p<.05$; group difference, $t_{(27)}=2.770, p<.01$ ) (Fig. 5C, Table 1). This difference was unlikely caused by measurement error in the preHD group, as variability in hand modulation was similar for both the preHD and control groups.

Importantly, right-hand modulation did not differ from zero for any group on MSL trials for which stopping preparation of the right hand was not necessary (preHD: $6.5 \pm 18.3 \%, t_{(13)}=1.320$, n.s.; controls: $3.5 \pm 24.3 \%, t<1$; group difference, $t<1$ ). Neither did right-hand modulation differ for zero for any group on JG trials for which stopping preparation is not necessary (preHD: $18.1 \pm 44.4 \%, t_{(13)}=1.524$, n.s.; controls: $2.9 \pm 13.4 \%, t<1$; group difference, $t_{(27)}=1.267$, n.s.) or on MSB trials also not requiring preparation for selective stopping (preHD: $9.8 \pm$ $23.7 \%, t_{(13)}=1.555$, n.s.; controls: $0.5 \pm 10.2 \%, t<1$; group difference, $t_{(27)}=1.405$, n.s.).

Notably, structural MRI confirmed basal ganglia damage in the preHD group. In a previous imaging study (2.6土.2 years prior) (Majid et al., 2011b), 9 of the current 14 preHD subjects had received T1 scans. Here, we compare volumes of seven subcortical regions (accumbens, amygdala, caudate, hippocampus, pallidum, putamen, and thalamus) in these nine current subjects versus the 22 controls in that study. Region-by-Group ANOVA showed a significant interaction $\left(F_{(4.196,29)}=2.414, p<0.05\right.$, with Huynh-Feldt correction), as well as significant effects for 
Table 3. Experiment 1 Activation coordinates for the Outright-Stopping phase

\begin{tabular}{lllrrrr}
\hline Contrast & Region & Side & $x$ & \multicolumn{1}{c}{ y } & Z & Z-max \\
\hline MSR + L (Stop $>$ Go) $)$ & Orbitofrontal cortex & $\mathrm{L}$ & -32 & 22 & -10 & 5.46 \\
& Insular cortex & $\mathrm{R}$ & 38 & 20 & -8 & 5.18 \\
& Caudate & $\mathrm{R}$ & 10 & 6 & 2 & 5.08 \\
& Occipital fusiform gyrus & $\mathrm{R}$ & 22 & -88 & -10 & 4.97 \\
& Premotor cortex & $\mathrm{R}$ & 38 & 4 & 28 & 4.93 \\
& Paracingulate gyrus & $\mathrm{R}$ & 8 & 20 & 42 & 4.76 \\
& Inferior frontal cortex & $\mathrm{R}$ & 52 & 10 & 6 & 4.75 \\
& Occipital fusiform gyrus & $\mathrm{L}$ & -28 & -88 & -12 & 4.71 \\
& Insular cortex & $\mathrm{L}$ & -34 & 18 & -6 & 4.59 \\
& Angular gyrus & $\mathrm{R}$ & 36 & -50 & 36 & 4.46 \\
& Caudate & $\mathrm{L}$ & -12 & 8 & 4 & 4.43 \\
& Accumbens & $\mathrm{R}$ & 12 & 12 & -6 & 4.25 \\
& PreSMA & $\mathrm{R}$ & 4 & 20 & 50 & 4.10 \\
& Pallidum & $\mathrm{R}$ & 14 & 6 & 2 & 3.98 \\
Parametric analysis of & Putamen & $\mathrm{R}$ & 16 & 10 & 0 & 3.94 \\
MSR + LStop trials and & Caudate & $\mathrm{L}$ & -12 & 4 & 18 & 3.30 \\
interference RT & Caudate & $\mathrm{R}$ & 14 & 14 & 14 & 3.00 \\
MSB (Stop $>$ G0) & Orbitofrontal cortex & $\mathrm{R}$ & 34 & 18 & -18 & 4.11 \\
& Inferior frontal & $\mathrm{R}$ & 48 & 20 & 4 & 3.60 \\
& gyrus & & & & & \\
& Insular cortex & $\mathrm{R}$ & 34 & 24 & 0 & 3.27 \\
\hline
\end{tabular}

Region $\left(F_{(6,29)}=1447, p<0.001\right)$ and $\operatorname{Group}\left(F_{(1,29)}=5.981\right.$, $p=0.021)$. The subset of nine preHD had smaller volumes in the putamen (percentage of individual intracranial volume; preHD, $0.59 \pm .06 \%$; controls, $0.67 \pm .06 \%$; $\left.t_{(29)}=3.135 ; p<.007\right)$ and pallidum (preHD, $0.20 \pm .02 \%$; controls, $0.23 \pm .02 \%$ of ICV; $\left.t_{(29)}=3.054 ; p<.007\right)$ but not in the other five subcortical regions (Fig. 5D, Table 4). These differences were significant even after strict Bonferroni's correction for seven multiple comparisons. Although it is likely that there was progressive atrophy during this period to other structures, these were likely other areas of the striatum such as the caudate and accumbens, rather than other subcortical regions (Aylward et al., 2010, Stoffers et al., 2010, van den Bogaard et al., 2011).

\section{Discussion}

We investigated the neural correlates of proactive selective stopping, a complex yet crucial everyday behavior that requires selective control of one's actions through advanced planning. In Experiment 1, single-pulse TMS of the right hand indexed the top-down effect of stopping goals in suppressing motor channels of the hand that might have to stop. Importantly, those subjects who suppressed the relevant hand early in the trial had greater functional activation in the striatum, pallidum, and preSMA locked to the cue in the subsequent fMRI session. In the outrightstopping phase, fMRI again revealed striatal and pallidal activation for selective stopping and, moreover, that the degree of striatal activation correlated with the degree of behavioral stopping selectivity. Finally, we repeated a version of the TMS study in a preHD group (with basal ganglia volume reductions) and matched controls. Consistent with the putative importance of the striatum and pallidum to proactive selective stopping, TMS revealed proactive hand suppression in controls but not the preHD group, and the latter were also behaviorally impaired at selective stopping.

\section{Proactive selective suppression engages striatum, pallidum, and preSMA}

The top-down influence of stopping goals on motor channels consistently leads to proactive motor suppression in healthy sub- jects, shown in a similar paradigm (Cai et al., 2011) and, indeed, replicated in the current Experiment 2 control subjects. Yet Experiment 1 did not show this at the group level. We suppose the high intersubject variability in proactive suppression was attributable to the much slower task design (needed for fMRI), which now meant that some subjects probably only implemented proactive suppression close to the go-signal, or even after it, rather than close to the cue. The fMRI peristimulus analysis also provides qualitative support this interpretation.

Notably, preSMA activation correlated with the degree of proactive hand suppression measured by TMS. This suggests that the preSMA may have a top-down influence over the basal ganglia to "set up" inhibitory response channels later triggered by the stopsignal. Such a role for the preSMA is consistent with the many studies that have implicated it in proactive stopping (Coxon et al., 2009, Chen et al., 2010, Stuphorn and Emeric, 2012, Swann et al., 2012, Zandbelt et al., 2012). The preSMA is also connected to both the rIFC (Johansen-Berg, 2010, Coxon et al., 2012, King et al., 2012, Swann et al., 2012), a node important for outright stopping (Aron et al., 2004, Chikazoe et al., 2007), and the striatum (Parthasarathy et al., 1992, Inase et al., 1999). Several studies specifically implicate the preSMA and striatum in the speedaccuracy trade-off (Forstmann et al., 2010, Forstmann et al., 2011), a form of proactive control.

Because fMRI findings are merely correlational, we sought to establish that the striatum and pallidum are necessary for proactive selective stopping by studying preHD subjects (Experiment 2 ). In preHD, there are frank basal ganglia volume reductions, particularly for the striatum and pallidum (Aylward et al., 2004, Hobbs et al., 2009, Tabrizi et al., 2009, Paulsen et al., 2010, Majid et al., 2011a, Majid et al., 2011b). In the current study, 9 of the 14 preHD subjects had confirmed volume reductions in the putamen and pallidum from a previous study (Majid et al., 2011b), and this is likely true of the entire group.

Consistent with our predictions, the preHD group showed no proactive hand suppression (indexed by TMS) versus controls and had an elongated Stopping Interference Effect (even when scaling for general slowing). These specific impairments occurred in the context of otherwise satisfactory task performance and cognitive examination scores similar to controls. Such preHD impairments may relate to difficulties in translating declarative working memory goals into a striatally mediated proactive influence over motor channels.

\section{Outright selective stopping}

We hypothesized that the network of brain regions implicated in preparing to stop could serve as a "proactive inhibitory set" (Aron, 2011), which can be triggered when stopping is later needed. Consistent with this, basal ganglia and preSMA activation recurred when outright stopping was required. Moreover, there was rIFC activation, not seen in any preparatory contrast. Whether the rIFC is important for proactive response control, and for which kinds of response control, is still unclear. Similar to the current findings, some other studies question whether rIFC is activated proactively (e.g., Zandbelt et al., 2012), whereas others do show a rIFC role in, for example, anticipation-related slowing (Jahfari et al., 2010, Swann et al., 2012).

Here we also show that when stopping selectively, the degree of behavioral selectivity correlated with the degree of striatal activation on a subject-by-subject basis. Notably, the dorsal caudate focus of this activation coincided with regions activated when contrasting preparation for selective versus nonselective stopping. This reinforces the notion that these regions are important 
A

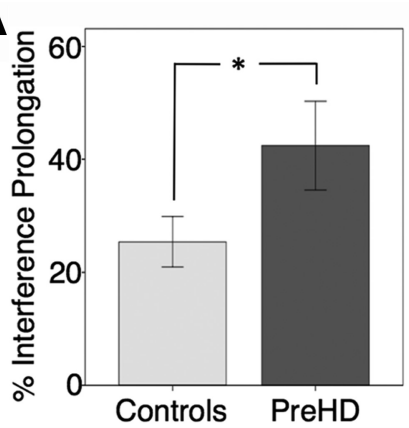

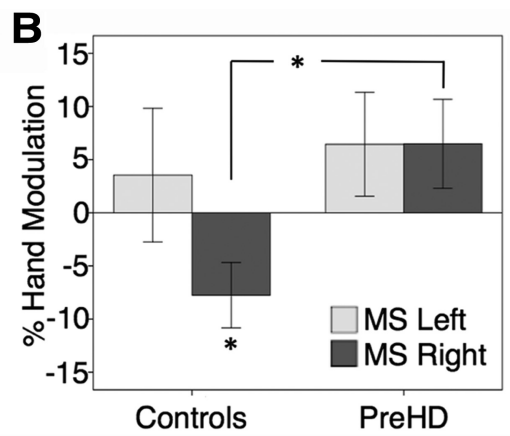

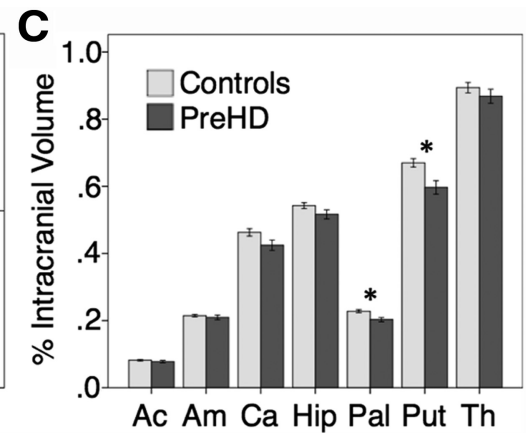

Figure 5. Experiment 2: preHD versus controls. $\boldsymbol{A}$, Less selective stopping. When stopping one hand, the preHD group took longer to continue with the other hand even when scaling for Go RT. The percentage of interference prolongation was calculated as follows: Interference (milliseconds)/MSR $+\mathrm{L}$ Go RT (milliseconds) $\times 100 \%$. $\boldsymbol{B}$, TMS suppression differences. Proactive selective suppression in Experiment 2 on MSR trials (when the right hand must prepare to stop) was identified only in controls (negative hand modulation to the Null baseline), whereas no such suppression occurred in preHD. On MSL trials, when the right hand need not stop, right-hand excitability did not differ significantly from the Null baseline in either group. Percent Hand Modulation was calculated as such: (Maybe Stop MEP - Null MEP)/Null MEP $\times 100 \%$.C, Subcortical volume differences: smaller brain volumes in 9 of the 14 preHD subjects who took part in a structural imaging study 2.6 years prior. Compared with the 22 controls in that study, the preHD subjects showed reduced volumes (normalized as a percentage of individual intracranial volume) in the putamen and pallidum after Bonferroni's correction. Ac, Accumbens; Am, amygdala; Ca, caudate; Hip, hippocampus; Pal, pallidum; Put, putamen; Th, thalamus. Error bars represent one standard error of the mean. Asterisks represent significant differences at the $p<0.05$ level.

Table 4. PreHD volumetric data

\begin{tabular}{lllll}
\hline Volumetric data (\% ICV $)$ & Controls $(n=22)$ & $\operatorname{PreHD}(n=9)$ & $t_{(29)}$ & $p$ \\
\hline Accumbens & $0.08 \pm 0.01$ & $0.08 \pm 0.01$ & $<1$ & n.s. \\
Amygdala & $0.21 \pm 0.02$ & $0.21 \pm 0.02$ & $<1$ & n.s. \\
Caudate & $0.46 \pm 0.05$ & $0.42 \pm 0.05$ & 1.781 & 0.085 \\
Hippocampus & $0.54 \pm 0.04$ & $0.52 \pm 0.04$ & 1.525 & n.s. \\
Pallidum & $0.23 \pm 0.02$ & $0.20 \pm 0.02$ & 2.932 & $0.007^{a}$ \\
Putamen & $0.67 \pm 0.06$ & $0.60 \pm 0.06$ & 3.009 & $0.005^{a}$ \\
Thalamus & $0.89 \pm 0.07$ & $0.87 \pm 0.06$ & $<1$ & n.s. \\
\hline
\end{tabular}

Volumetric data given as the sum of bilateral structures normalized as a percentage of ICV (\%ICV). Data from second visit described in Majid et al. (2012, 2011b), which included 9 of the 14 preHD subjects studied here compared to 22 matched controls.

${ }^{a}$ Significant after strict Bonferroni's correction for seven comparisons.

for the selectivity of stopping. This result also suggests that stopping in this paradigm is mechanistically selective, as opposed to merely stopping all and then restarting one response, which might be the case for other behavioral paradigms that purport to measure behaviorally selective stopping but do not allow for advanced preparation (cf. Bissett and Logan, 2013). Two other considerations bear on this. First, the activation in the abovementioned dorsal caudate was related to the selectivity of stopping but not to merely hand movement when going. Second, the Stopping Interference Effect in Experiment 1 was a mere 60 ms, on average, with many subjects having a value close to zero, implying almost perfectly selective stopping.

Our findings point to some heterogeneity in the striatum. Although a more dorsal caudate region was implicated in the selective aspect of stopping (see above), a more ventral striatal region was implicated in motor suppression (i.e., related to proactive hand suppression in advance of stopping and for outright stopping; compare Figs. $2 B, 4 A$ ).

\section{Human evidence for the indirect pathway}

We propose that striatal and pallidal activation in this study is a functional index of indirect pathway involvement in mechanistically selective stopping for the following reasons. First, we linked striatal activation to a form of selective motor suppression, as do neurophysiological studies in primates (Ford and Everling, 2009, Watanabe and Munoz, 2010) and rodents (Bryden et al., 2012). Second, we find selective stopping impairments in a population thought to primarily have indirect pathway degeneration in the early stage of disease (Vonsattel et al., 1985, Albin et al., 1995, Starr et al., 2008). Indeed, hyperkinetic (disinhibitory) symptoms in early-stage HD are classically thought to arise from an impaired ability to stop specific movements (Penney and Young, 1983). Third, this form of behaviorally selective stopping has been associated with longer SSRT compared with simple nonselective stopping (Aron and Verbruggen, 2008, Claffey et al., 2010), which is consistent with delays expected from the greater number of synapses in the indirect pathway versus the hyperdirect pathway that is implicated in simple reactive stopping (Magill et al., 2004, Aron and Poldrack, 2006, Ray et al., 2009).

We acknowledge, however, that more definitive proof for the indirect pathway is required. This could include (1) highresolution imaging of nodes believed specific to this pathway (e.g., external globus pallidus) (Mattfeld et al., 2011) during selective stopping; (2) D2 receptor imaging (Black et al., 1997) to quantify indirect pathway integrity in relation to individual variation in selective stopping behavior/physiology; and (3) parallel task development with neurophysiology in rodents and monkeys, as has been done for simple stopping (Boucher et al., 2007, Leventhal et al., 2012, Stuphorn and Emeric, 2012).

\section{Implications}

The results have timely practical implications, allowing for further study of the indirect pathway in humans and connecting these studies to the burgeoning, sophisticated studies of basal ganglia pathways using optogenetics in mice (Kravitz et al., 2012) and neurophysiology in rodents (Leventhal et al., 2012) and monkeys (Kim et al., 2012). Furthermore, the development of functional indices of the putative indirect pathway could have clinical import for neurodegenerative disorders such as Huntington's disease, where there is an urgent need for biomarkers for subtle functional changes before there is major irreversible cell loss (Ross and Tabrizi, 2011).

The results have theoretical implications too. Whereas it has been argued that a major role for striatum is to weight particular response channels in advance of action (i.e., a proactive "response set"; Robbins and Brown, 1990, Hikosaka et al., 2006), the current data argue the striatum can also be used to set up a proactive inhibitory set. Specifically, we propose that frontal cortical regions such as the preSMA drive the implementation of inhibitory response channels in the striatum and that these are then 
triggered subsequently when stopping is needed. These results also support a psychological distinction between declarative versus procedural working memory (instantiated here as proactive suppression) (cf. Oberauer, 2009). This fits with recent theories regarding the striatal role in working memory (Scimeca and $\mathrm{Ba}-$ dre, 2012) by showing that declarative working memory in the cortex could be "translated" into a procedural working memory plan in the striatum.

\section{Summary}

We show that subjects use their goals to stop particular response tendencies by proactively suppressing those response channels. We also show that this corresponds to striatal and pallidal activation and that damage to these structures affects selective response suppression.

\section{Notes}

Supplemental material for this article is available at www.aronlab. org/Pubs/hd_tms.pdf. This provides information about an additional TMS experiment done in the preHD and control groups of the current paper. This material has not been peer reviewed.

\section{References}

Albin RL, Young AB, Penney JB (1995) The functional anatomy of disorders of the basal ganglia. Trends Neurosci 18:63-64. CrossRef Medline

Aron AR (2011) From reactive to proactive and selective control: developing a richer model for stopping inappropriate responses. Biol Psychiatry 69:e55-e68. CrossRef Medline

Aron AR, Poldrack RA (2006) Cortical and subcortical contributions to Stop signal response inhibition: role of the subthalamic nucleus. J Neurosci 26:2424-2433. CrossRef Medline

Aron AR, Verbruggen F (2008) Stop the presses: dissociating a selective from a global mechanism for stopping. Psychol Sci 19:1146-1153. CrossRef Medline

Aron AR, Robbins TW, Poldrack RA (2004) Inhibition and the right inferior frontal cortex. Trends Cogn Sci 8:170-177. CrossRef Medline

Aylward EH, Sparks BF, Field KM, Yallapragada V, Shpritz BD, Rosenblatt A, Brandt J, Gourley LM, Liang K, Zhou H, Margolis RL, Ross CA (2004) Onset and rate of striatal atrophy in preclinical Huntington disease. Neurology 63:66-72. CrossRef Medline

Aylward EH, Nopoulos PC, Ross CA, Langbehn DR, Pierson RK, Mills JA, Johnson HJ, Magnotta VA, Juhl AR, Paulsen JS, PREDICT-HD Investigators and Coordinators of Huntington Study Group (2010) Longitudinal change in regional brain volumes in prodromal Huntington disease. J Neurol Neurosurg Psychiatr 82:405-410. CrossRef Medline

Badry R, Mima T, Aso T, Nakatsuka M, Abe M, Fathi D, Foly N, Nagiub H, Nagamine T, Fukuyama H (2009) Suppression of human corticomotoneuronal excitability during the Stop-signal task. Clin Neurophysiol 120:1717-1723. CrossRef Medline

Bissett PG, Logan GD (2013) Selective stopping? Maybe not. J Exp Psychol Gen, in press.

Black KJ, Gado MH, Perlmutter JS (1997) PET measurement of dopamine D2 receptor-mediated changes in striatopallidal function. J Neurosci 17: 3168-3177. Medline

Boehler CN, Appelbaum LG, Krebs RM, Hopf JM, Woldorff MG (2010) Pinning down response inhibition in the brain-conjunction analyses of the Stop-signal task. Neuroimage 52:1621-1632. CrossRef Medline

Boucher L, Palmeri TJ, Logan GD, Schall JD (2007) Inhibitory control in mind and brain: an interactive race model of countermanding saccades. Psychol Rev 114:376-397. CrossRef Medline

Bryden DW, Burton AC, Kashtelyan V, Barnett BR, Roesch MR (2012) Response inhibition signals and miscoding of direction in dorsomedial striatum. Front Integr Neurosci 6:69. CrossRef Medline

Cai W, Oldenkamp C, Aron AR (2011) A proactive mechanism for selective suppression of response tendencies. J Neurosci 31:5965-5969. CrossRef Medline

Cai W, Oldenkamp CL, Aron AR (2012) Stopping speech suppresses the task-irrelevant hand. Brain Lang 120:412-415. CrossRef Medline

Chamberlain SR, Fineberg NA, Blackwell AD, Robbins TW, Sahakian BJ (2006) Motor inhibition and cognitive flexibility in obsessive- compulsive disorder and trichotillomania. Am J Psychiatry 163:12821284. CrossRef Medline

Chambers CD, Garavan H, Bellgrove MA (2009) Insights into the neural basis of response inhibition from cognitive and clinical neuroscience. Neurosci Biobehav Rev 33:631-646. CrossRef Medline

Chen X, Scangos KW, Stuphorn V (2010) Supplementary motor area exerts proactive and reactive control of arm movements. J Neurosci 30:1465714675. CrossRef Medline

Chikazoe J (2010) Localizing performance of go/no-go tasks to prefrontal cortical subregions. Curr Opin Psychiatry 23:267-272. CrossRef Medline

Chikazoe J, Konishi S, Asari T, Jimura K, Miyashita Y (2007) Activation of right inferior frontal gyrus during response inhibition across response modalities. J Cogn Neurosci 19:69-80. CrossRef Medline

Claffey MP, Sheldon S, Stinear CM, Verbruggen F, Aron AR (2010) Having a goal to stop action is associated with advance control of specific motor representations. Neuropsychologia 48:541-548. CrossRef Medline

Coxon JP, Stinear CM, Byblow WD (2009) Stop and go: the neural basis of selective movement prevention. J Cogn Neurosci 21:1193-1203. CrossRef Medline

Coxon JP, Van Impe A, Wenderoth N, Swinnen SP (2012) Aging and inhibitory control of action: cortico-subthalamic connection strength predicts stopping performance. J Neurosci 32:8401-8412. CrossRef Medline

Devanne H, Lavoie BA, Capaday C (1997) Input-output properties and gain changes in the human corticospinal pathway. Exp Brain Res 114:329-338. CrossRef Medline

Fischl B, Salat DH, Busa E, Albert M, Dieterich M, Haselgrove C, van der Kouwe A, Killiany R, Kennedy D, Klaveness S, Montillo A, Makris N, Rosen B, Dale AM (2002) Whole brain segmentation: automated labeling of neuroanatomical structures in the human brain. Neuron 33:341-355. CrossRef Medline

Fischl B, Salat DH, van der Kouwe AJW, Makris N, Ségonne F, Quinn BT, Dale AM (2004) Sequence-independent segmentation of magnetic resonance images. Neuroimage 23 [Suppl 1]:S69-S84.

Folstein MF, Folstein SE, McHugh PR (1975) “Mini-mental state." A practical method for grading the cognitive state of patients for the clinician. J Psychiatr Res 12:189-198. CrossRef Medline

Ford KA, Everling S (2009) Neural activity in primate caudate nucleus associated with pro- and antisaccades. J Neurophysiol 102:2334-2341. CrossRef Medline

Forstmann BU, Anwander A, Schäfer A, Neumann J, Brown S, Wagenmakers EJ, Bogacz R, Turner R (2010) Cortico-striatal connections predict control over speed and accuracy in perceptual decision making. Proc Natl Acad Sci U S A 107:15916-15920. CrossRef Medline

Forstmann BU, Tittgemeyer M, Wagenmakers EJ, Derrfuss J, Imperati D, Brown S (2011) The speed-accuracy tradeoff in the elderly brain: a structural model-based approach. J Neurosci 31:17242-17249. CrossRef Medline

Greenhouse I, Oldenkamp CL, Aron AR (2012) Stopping a response has global or nonglobal effects on the motor system depending on preparation. J Neurophysiol 107:384-392. CrossRef Medline

Hazrati LN, Parent A (1992) The striatopallidal projection displays a high degree of anatomical specificity in the primate. Brain Res 592:213-227. CrossRef Medline

Hikosaka O, Nakamura K, Nakahara H (2006) Basal ganglia orient eyes to reward. J Neurophysiol 95:567-584. CrossRef Medline

Hobbs NZ, Henley SM, Wild EJ, Leung KK, Frost C, Barker RA, Scahill RI, Barnes J, Tabrizi SJ, Fox NC (2009) Automated quantification of caudate atrophy by local registration of serial MRI: evaluation and application in Huntington's disease. Neuroimage 47:1659-1665. CrossRef Medline

Inase M, Tokuno H, Nambu A, Akazawa T, Takada M (1999) Corticostriatal and corticosubthalamic input zones from the presupplementary motor area in the macaque monkey: comparison with the input zones from the supplementary motor area. Brain Res 833:191-201. CrossRef Medline

Jahfari S, Stinear CM, Claffey M, Verbruggen F, Aron AR (2010) Responding with restraint: what are the neurocognitive mechanisms? J Cogn Neurosci 22:1479-1492. CrossRef Medline

Jahfari S, Waldorp L, van den Wildenberg WP, Scholte HS, Ridderinkhof KR, Forstmann BU (2011) Effective connectivity reveals important roles for both the hyperdirect (fronto-subthalamic) and the indirect (frontostriatal-pallidal) fronto-basal ganglia pathways during response inhibition. J Neurosci 31:6891-6899. CrossRef Medline 
Jenkinson M, Smith S (2001) A global optimisation method for robust affine registration of brain images. Med Image Anal 5:143-156. CrossRef Medline

Jenkinson M, Bannister P, Brady M, Smith S (2002) Improved optimization for the robust and accurate linear registration and motion correction of brain images. Neuroimage 17:825-841. CrossRef Medline

Johansen-Berg H (2010) Behavioural relevance of variation in white matter microstructure. Curr Opin Neurol 23:351-358. CrossRef Medline

Kim S, Cai X, Hwang J, Lee D (2012) Prefrontal and striatal activity related to values of objects and locations. Front Neurosci 6:108. CrossRef Medline

King AV, Linke J, Gass A, Hennerici MG, Tost H, Poupon C, Wessa M (2012) Microstructure of a three-way anatomical network predicts individual differences in response inhibition: a tractography study. Neuroimage 59: 1949-1959. CrossRef Medline

Kravitz AV, Tye LD, Kreitzer AC (2012) Distinct roles for direct and indirect pathway striatal neurons in reinforcement. Nat Neurosci 15:816-818. CrossRef Medline

Langbehn DR, Brinkman RR, Falush D, Paulsen JS, Hayden MR, International Huntington's Disease Collaborative Group (2004) A new model for prediction of the age of onset and penetrance for Huntington's disease based on CAG length. Clin Genet 65:267-277. CrossRef Medline

Langbehn DR, Hayden MR, Paulsen JS, PREDICT-HD Investigators of the Huntington Study Group (2010) CAG-repeat length and the age of onset in Huntington disease (HD): a review and validation study of statistical approaches. Am J Med Genet B Neuropsychiatr Genet 153B:397-408. CrossRef Medline

Leventhal DK, Gage GJ, Schmidt R, Pettibone JR, Case AC, Berke JD (2012) Basal ganglia beta oscillations accompany cue utilization. Neuron 73:523536. CrossRef Medline

Magill PJ, Sharott A, Bevan MD, Brown P, Bolam JP (2004) Synchronous unit activity and local field potentials evoked in the subthalamic nucleus by cortical stimulation. J Neurophysiol 92:700-714. CrossRef Medline

Majid DS, Stoffers D, Sheldon S, Hamza S, Thompson WK, Goldstein J, Corey-Bloom J, Aron AR (2011a) Automated structural imaging analysis detects premanifest Huntington's disease neurodegeneration within 1 year. Mov Disord 26:1481-1488. CrossRef Medline

Majid DS, Aron AR, Thompson WK, Sheldon S, Hamza S, Stoffers D, Holland D, Goldstein J, Corey-Bloom J, Dale AM (2011b) Basal ganglia atrophy in prodromal Huntington's disease is detectable over one year using automated segmentation. Mov Disord 26:2544-2551. CrossRef Medline

Majid DS, Cai W, George JS, Verbruggen F, Aron AR (2012) Transcranial magnetic stimulation reveals dissociable mechanisms for global versus selective corticomotor suppression underlying the stopping of action. Cereb Cortex 22:363-371. CrossRef Medline

Mattfeld AT, Gluck MA, Stark CE (2011) Functional specialization within the striatum along both the dorsal/ventral and anterior/posterior axes during associative learning via reward and punishment. Learn Mem 18: 703-711. CrossRef Medline

Mink JW (1996) The basal ganglia: focused selection and inhibition of competing motor programs. Prog Neurobiol 50:381-425. CrossRef Medline

Nasreddine ZS, Phillips NA, BédirianV, Charbonneau S, Whitehead V, Collin I, Cummings JL, Chertkow H (2005) The Montreal Cognitive Assessment, MoCA: a brief screening tool for mild cognitive impairment. J Am Geriatr Soc 53:695-699. CrossRef Medline

Oberauer K (2009) Design for a working memory. Psychology of learning and motivation. Adv Res Theory 51:45-100.

Ollinger JM, Corbetta M, Shulman GL (2001) Separating processes within a trial in event-related functional MRI. Neuroimage 13:218-229. CrossRef Medline

Parthasarathy HB, Schall JD, Graybiel AM (1992) Distributed but convergent ordering of corticostriatal projections: analysis of the frontal eye field and the supplementary eye field in the macaque monkey. J Neurosci 12:4468-4488. Medline

Paulsen JS, Nopoulos PC, Aylward E, Ross CA, Johnson H, Magnotta VA, Juhl A, Pierson RK, Mills J, Langbehn D, Nance M, PREDICT-HD Investigators and Coordinators of the Huntington's Study Group (HSG) (2010) Striatal and white matter predictors of estimated diagnosis for Huntington disease. Brain Res Bull 82:201-207. CrossRef Medline
Penney JB Jr, Young AB (1983) Speculations on the functional anatomy of basal ganglia disorders. Annu Rev Neurosci 6:73-94. CrossRef Medline

Ray NJ, Jenkinson N, Brittain J, Holland P, Joint C, Nandi D, Bain PG, Yousif N, Green A, Stein JS, Aziz TZ (2009) The role of the subthalamic nucleus in response inhibition: evidence from deep brain stimulation for Parkinson's disease. Neuropsychologia 47:2828-2834. CrossRef Medline

Robbins TW, Brown VJ (1990) The role of the striatum in the mental chronometry of action: a theoretical review. Rev Neurosci 2:181-214. CrossRef Medline

Ross CA, Tabrizi SJ (2011) Huntington's disease: from molecular pathogenesis to clinical treatment. Lancet Neurol 10:83-98. CrossRef Medline

Rossi S, Hallett M, Rossini PM, Pascual-Leone A, Safety of TMS Consensus Group (2009) Safety, ethical considerations, and application guidelines for the use of transcranial magnetic stimulation in clinical practice and research. Clin Neurophysiol 120:2008-2039. CrossRef Medline

Rossini PM, Barker AT, Berardelli A, Caramia MD, Caruso G, Cracco RQ, Dimitrijevic MR, Hallett M, Katayama Y, Lücking $\mathrm{CH}$, Maertens de Noordhout AL, Marsden CD, Murray NMF, Rothwell JC, Swash M, Tomberg C (1994) Non-invasive electrical and magnetic stimulation of the brain, spinal cord and roots: basic principles and procedures for routine clinical application. Report of an IFCN committee. Electroencephalogr Clin Neurophysiol 91:79-92. CrossRef Medline

Scimeca JM, Badre D (2012) Striatal contributions to declarative memory retrieval. Neuron 75:380-392. CrossRef Medline

Starr PA, Kang GA, Heath S, Shimamoto S, Turner RS (2008) Pallidal neuronal discharge in Huntington's disease: support for selective loss of striatal cells originating the indirect pathway. Exp Neurol 211:227-233. CrossRef Medline

Stinear CM, Byblow WD (2004) Impaired modulation of intracortical inhibition in focal hand dystonia. Cereb Cortex 14:555-561. CrossRef Medline

Stoffers D, Sheldon S, Kuperman JM, Goldstein J, Corey-Bloom J, Aron AR (2010) Contrasting gray and white matter changes in preclinical Huntington disease: an MRI study. Neurology 74:1208-1216. CrossRef Medline

Stuphorn V, Emeric EE (2012) Proactive and reactive control by the medial frontal cortex. Front Neuroeng 5:9. CrossRef Medline

Swann NC, Cai W, Conner CR, Pieters TA, Claffey MP, George JS, Aron AR, Tandon N (2012) Roles for the pre-supplementary motor area and the right inferior frontal gyrus in stopping action: electrophysiological responses and functional and structural connectivity. Neuroimage 59: 2860-2870. CrossRef Medline

Tabrizi SJ, Langbehn DR, Leavitt BR, Roos RA, Durr A, Craufurd D, Kennard C, Hicks SL, Fox NC, Scahill RI, Borowsky B, Tobin AJ, Rosas HD, Johnson H, Reilmann R, Landwehrmeyer B, Stout JC, TRACK-HD investigators (2009) Biological and clinical manifestations of Huntington's disease in the longitudinal TRACK-HD study: cross-sectional analysis of baseline data. Lancet Neurol 8:791-801. CrossRef Medline

van den Bogaard SJA, Dumas EM, Acharya TP, Johnson H, Langbehn DR, Scahill RI, Tabrizi SJ, van Buchem MA, van der Grond J, Roos RAC, TRACK-HD Investigator Group (2011) Early atrophy of pallidum and accumbens nucleus in Huntington's disease. J Neurol 258:412-420. CrossRef Medline

Verbruggen F, Logan GD (2008) Response inhibition in the stop-signal paradigm. Trends Cogn Sci 12:418-424. CrossRef Medline

Verbruggen F, Logan GD (2009) Models of response inhibition in the stopsignal and stop-change paradigms. Neurosci Biobehav Rev 33:647-661. CrossRef Medline

Vonsattel JP, Myers RH, Stevens TJ, Ferrante RJ, Bird ED, Richardson EP Jr (1985) Neuropathological classification of Huntington's disease. J Neuropathol Exp Neurol 44:559-577. CrossRef Medline

Watanabe M, Munoz DP (2010) Saccade suppression by electrical microstimulation in monkey caudate nucleus. J Neurosci 30:2700-2709. CrossRef Medline

Wilcox RR (2001) Fundamentals of modern statistical methods: substantially improving power and accuracy. New York: Springer.

Zandbelt BB, Bloemendaal M, Neggers SF, Kahn RS, Vink M (2012) Expectations and violations: delineating the neural network of proactive inhibitory control. Hum Brain Mapp. Advance online publication. Retrieved Feb. 26, 2013. doi:10.1002/hbm.22047. CrossRef 